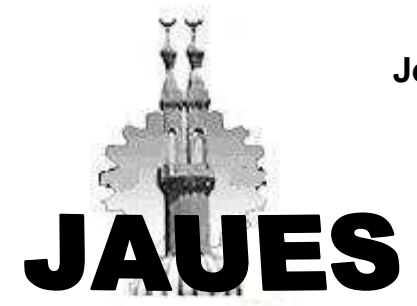

Journal of Al-Azhar University Engineering Sector

Vol.16, No. 60, July 2021, 553- 564

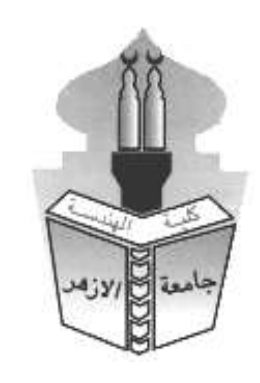

\title{
INVESTIGATING THE IMPACT OF HALF PIPE BARRIERS ON HYDRODYNAMICS OF WAVES
}

\author{
Mohamed I. Mohamed \\ Department of Civil Engineering, Faculty of Engineering, Al-Azhar University \\ *Corresponding Author's E-mail: anasamer3337@azhar.edu.eg \\ Received: 12 April $2021 \quad$ Accepted: 05 June 2021
}

\begin{abstract}
In the framework of the integrated coastal zone management (ICZM) project and implementing innovative breakwaters (half pipes barrier) in Egypt, this research was initiated in order to determine their impact on hydrodynamics of waves, numerically. Primarily, literature in the field of breakwaters were assembled and scrutinized. A numerical model (Flow 3D) was selected to be implemented. Several barriers, with different characteristics, were modeled and wave hydrodynamics properties (i.e. reflection and transmission) were designated. Furthermore, the velocity beneath and behind the barrier so as pressure were numerically modeled. The results were analyzed and presented on graphs. Furthermore the results were discussed, from which conclusions so as recommendations were obtained, where specific dimensions for the barrier were designated. Moreover, the research results indicated that higher velocities were recorded for deeper barrier draft. In addition, the research results flagged-out that the more its draft, the greater is its efficiency and the less is the wave transmission. Moreover, the results indicated that the proposed barrier dissipates the energy of the oblique waves more than orthogonal waves by about 5\%. Innovative about this investigation is the prioritization of implementing deeper drafts to help in reducing the wave height behind the barrier, which leads to an economic implementation of barriers.
\end{abstract}

Keywords:

Half pipe, Barriers, Transmission, Reflection, Numerical.

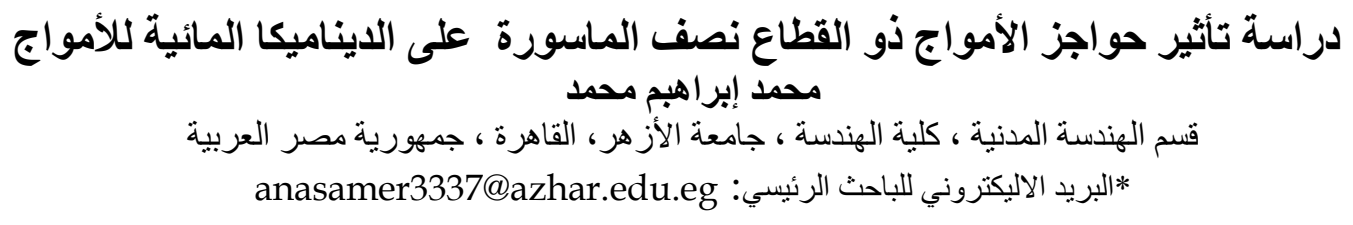




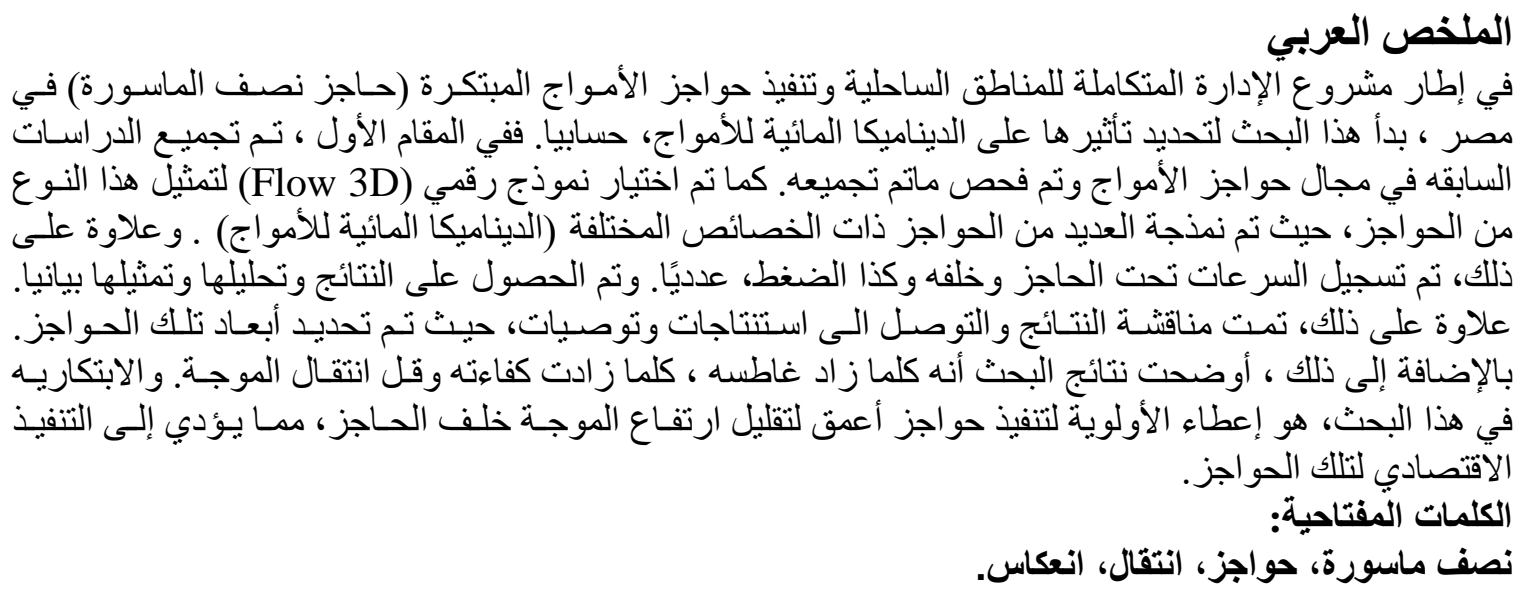

\section{INTRODUCTION}

Mankind is after innovation in all branches of science, especially in the science related to the coast and the sea "Coastal Engineering". Mankind is very interested in developing an innovative breakwater, where breakwaters are structures that are built for coastal management and protecting against long-shore drift.

Traditionally, breakwaters have many types. Among them are vertical, slopping and composite breakwaters. They dissipate energy by reflection (impermeable vertical breakwaters) or by friction (permeable breakwaters). Recently, researchers are exerting tremendous effort to put forward to an innovative economic sustainable and efficient breakwater type.

Many researchers are involved in enhancing breakwaters' efficiency and establishing innovative types.

For example, Xi-zeng Zhao and Du Cheng, (2019) investigated solitary waves overtopping breakwater, experimentally so as numerically. They carried out 9 experimental models to investigate the impact of their beam height under variable water depths. The simulations were performed by a limited high-resolution- difference-modelsolution to Navier-Stoke (NS) equations. They measured the wave height, velocity, and pressure, where they found a big analogy between the numerical and experimental results. They carried out a parametric study numerically to study the impacts of their characteristics on the hydrodynamic properties in the breakwater vicinity.

In addition, Wang, J.D., He, G.H., You, R. and Liu, P.F., (2018) investigated solitary wave spread on an obstacle via a restricted-interpolation-definition (CIP) based on the Cartesian-Grid-method to solve the Navier-Stoke equations.

Furthermore, Nadji Chioukh et al, (2017) scrutinized the reflection so as transmission coefficients of regular waves of perforated-thin-walls, where the experimental work was performed in a wave flume. They examined the positions of a single perforated thin Plexiglas plate, where wave overtopping is prohibited while the incident waves are transmitted. The porosities were simulated by varying the perforation of the plates by boring additional holes in them. They tested parallel double-perforated-walls (chamber system). Several parameters were examined and the results were compared to the numerical model (MDBEM "Multi Domain Boundary Element Method") results.

Moreover, Ibrahim (2017) investigated the hydrodynamic performance of asymmetrical double-vertical-slotted-barriers, experimentally and numerically with Flow-3D. The 
experimental results designated their hydraulic performance and the numerical results were analogous to the experimental results.

In the context of implementing innovative breakwaters (half pipe barriers) in Egypt, this research was commenced with the impartial of determining their hydrodynamic efficiency, where they were numerically modeled; figure (1), to investigate their different characteristics.
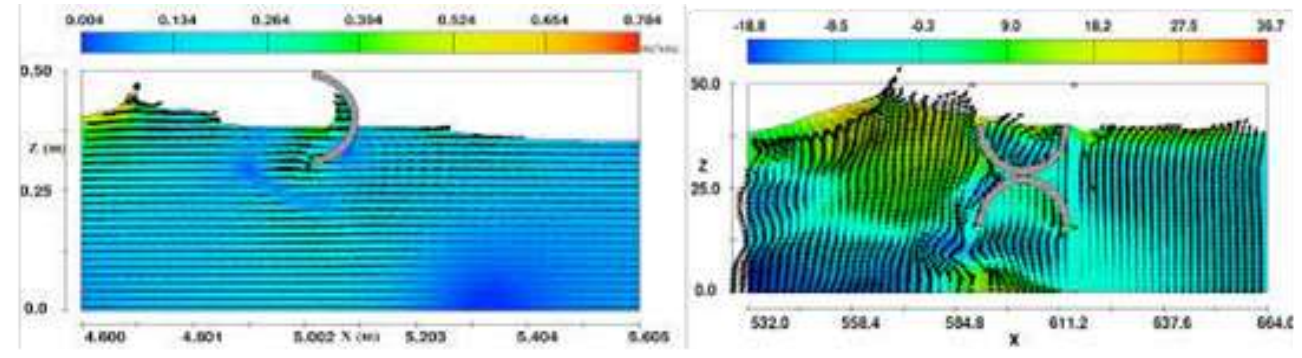

Figure (1) Modeling half pipe barriers numerically

\section{NUMMERICAL INVESTIGATION}

This section elaborates the performed numerical investigation, where the simulated flume, tested models, the performed simulation program, the implemented numerical model and numerical simulations are presented, as follows:

\subsection{SIMULATED FLUME}

The simulated flume was $12.0 \mathrm{~m}$ long and $0.4 \mathrm{~m}$ wide water channel. Its depth was $0.5 \mathrm{~m}$ at its beginning and $0.4 \mathrm{~m}$ at its end.

\subsection{TESTED MODELS}

A $20 \mathrm{~cm}$ long and $2 \mathrm{~cm}$ thick semi-circular pipe was tested. The model was tested in 2 types of flumes, where it was fixed in an E-shaped flume and in a Y-shaped flume; figure (2).

\subsection{PERFORMED SIMULATION PROGRAM}

The performed simulation program investigated the variation of the draft (D) and wave period (T). In addition, 2 wave angles were simulated. These were orthogonals to the barriers regular linear wave and at an angle $30^{\circ}$ to the barriers regular linear wave. Moreover, the incident wave (Hi) values were obtained from a previous laboratory study by Ibrahim (2017), table (1).

Table (1) Wave period, incident wave height, wave length and number, Ibrahim (2017)

\begin{tabular}{|l|l||l|l|l|l|l||}
\hline \hline wave period $(\mathrm{T})(\mathrm{sec})$. & 2.00 & 1.70 & 1.40 & 1.30 & 1.10 & 0.90 \\
\hline \hline wave incident $(\mathrm{Hi})(\mathrm{cm})$ & 4.20 & 5.30 & 6.70 & 8.20 & 10.00 & 13.00 \\
\hline \hline wave length $(\mathrm{L})(\mathrm{m})$ & 3.77 & 3.13 & 2.42 & 2.17 & 1.68 & 1.21 \\
\hline \hline wave number $(\mathrm{k})(1 / \mathrm{m})$ & 1.67 & 2.00 & 2.50 & 2.80 & 3.74 & 5.19 \\
\hline
\end{tabular}




\subsection{IMPLEMENTED NUMERICAL MODEL}

FLOW-3D was selected to be implemented. It is a flow modeling software appropriate for the investigated barriers. It is worldwide accepted that provided reasonable results, where many variables could be simulated without time consumption at economic cost. It is a fast CFD software that solves free-surface flow problems. It is highly-efficient that provides comprehensive solution with human-centric-support. FLOW-3D simulates regular linear so as nonlinear waves and irregular waves. Theoretically, Flow-3D describes fluid motion by non-linear, $2^{\text {nd }}$-order differential equations.

\subsection{NUMERICAL SIMULATIONS}

The breakwaters with its dimensions; figure (3), was numerically simulated and numerical solutions to the equations were obtained. The resulting equations were solved and an approximate solution to the problem was obtained via the equations of motion. A computational mesh or grid was discretized with a number of interconnected-elements in order to divide the physical space into several nodes to store the unknowns, figure (4). Boundary conditions were set; flow domain was divided into cells; a compromise was settled between constrains and an accurate solution was reached.

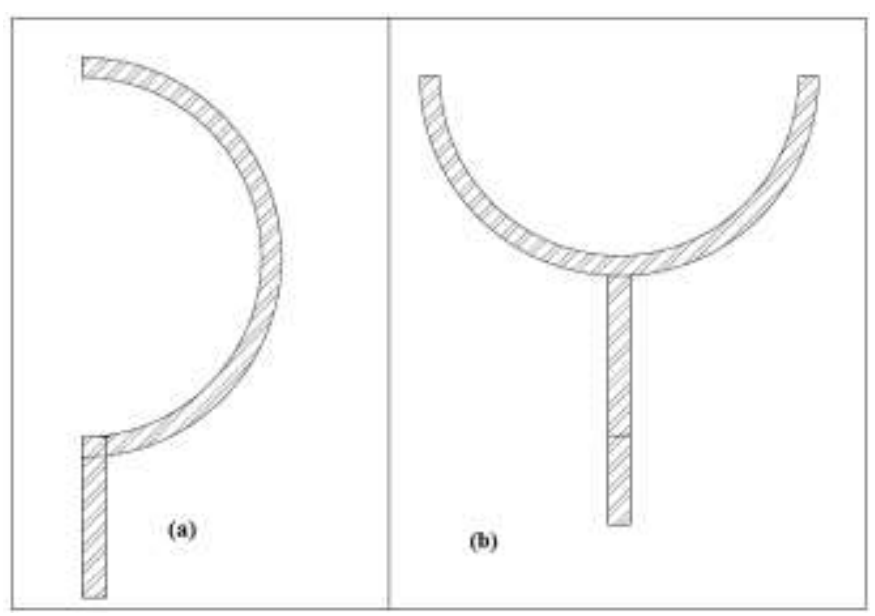

Figure (2) Simulated E-shaped and Y-shaped flumes

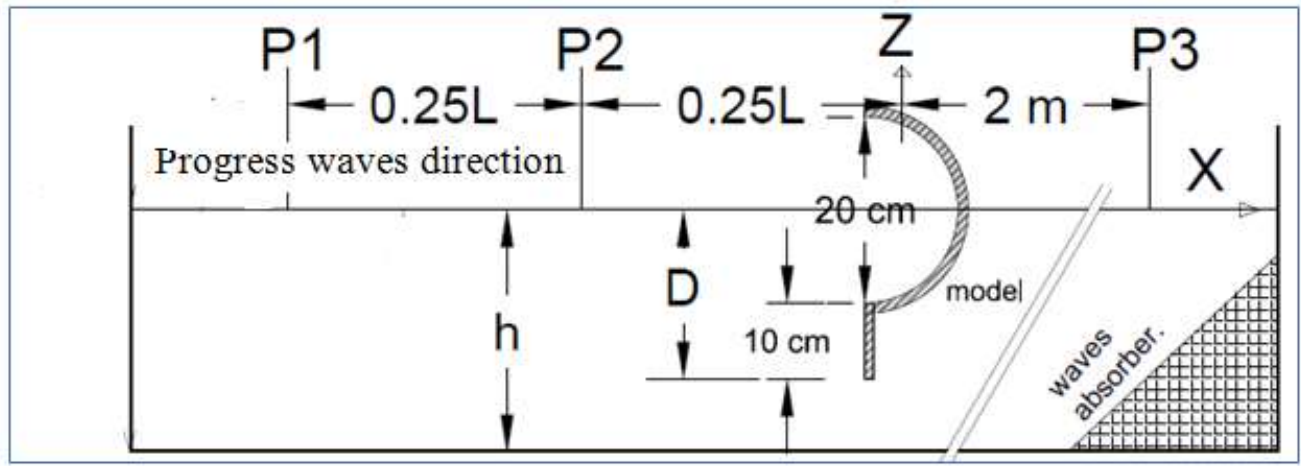

Figure (3) Modeled breakwater dimensions 


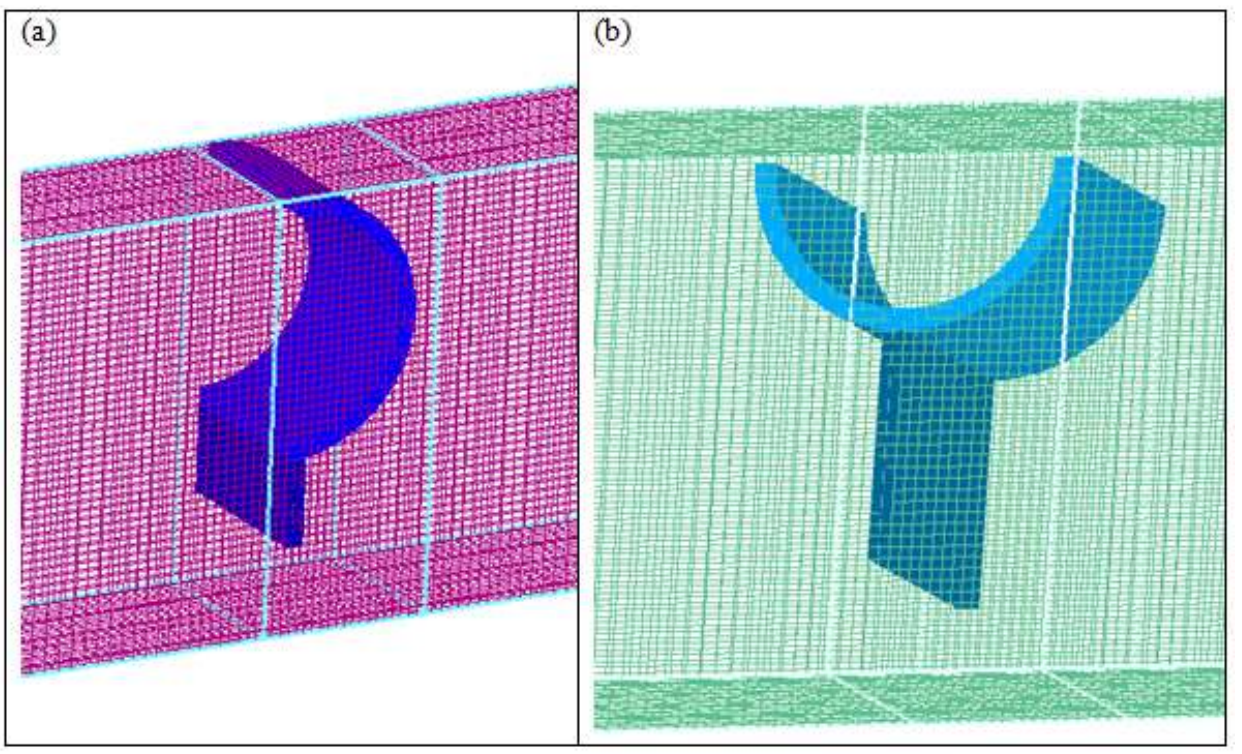

Figure (4) Meshing geometry in FLOW-3D for E-shaped and Y-shaped

\section{RESULTS ANALYSIS AND DISCUSSIONS}

Results for wave transmission, reflection, velocity and pressure were obtained. The obtained results were analyzed; presented on graphs, figure (4) to (9) and discussed, as follows:

- Figure (4) highlighted the simulation process for a barrier-less case (without barriers). The figure emphasized that the waves are regular and the velocity was high at the wave crest.

- Figure (5a) flagged-out that the transmission coefficient (Tc) decreases as $(\mathrm{kh})$ and the water depth $(\mathrm{h})$ increase, where $\mathrm{k}=2 \pi / \mathrm{L}$. In addition, it cleared out that the E-shaped flume provided lower transmission (Tc) than Y-shaped flume by 3-7\%.

- Figure (5b) designated that the reflection coefficient (Rc) increases as (kh) increases. Moreover, it flagged out that the E-shaped flume provided higher wave reflection $(\mathrm{Rc})$ values than the Y-shaped flume by 4-8\%.

- Figure (6a) pointed out that the E-shaped flume provided a lower transmission coefficient (Tc), at draft (D) of 0.75 (h) than at a draft (D) of 0.50 (h) by $10 \%$.

- Figure (6b) pointed out that the E-shaped flume provided a higher reflection coefficient (Rc), at draft (D) of 0.75 (h) than at a draft (D) of 0.50 (h) by $8 \%$.

- Figure (7) presented the values of the transmission coefficient (Tc) and the reflection coefficient $(\mathrm{Rc})$ at different wave angles for the $\mathrm{Y}$-shaped flume.

- Figure (7a) advocated that the transmission coefficient (Tc) of orthogonal waves are higher than the transmission coefficient (Tc) of the oblique wave at an angle of $30^{\circ}$ by $5 \%$.

- Figure (7b) highlighted that the reflection coefficient (Rc) of orthogonal waves are lower than the reflection coefficient (Tc) of the oblique wave at an angle of $30^{0}$ by $5 \%$.

- Figure (8a) indicated that as the breakwater draft increases, the maximum velocity increases, where the maximum velocity was $0.91 \mathrm{~m} / \mathrm{sec}$. 
- Figure $(8 b)$ designated that the same trend was also apparent for the maximum velocity of $0.96 \mathrm{~m} / \mathrm{sec}$.

- Figure (8c) flagged-out that the same trend was also apparent for the maximum velocity of $1.0 \mathrm{~m} / \mathrm{sec}$.

- Figure (9) presented FLOW-3D images, which indicated that the higher the reflection of waves, the greater the hydrodynamic pressure on the barrier.

From the graphs, obvious was that:

- The more the draft, the lower the transmission coefficient and the more the reflection coefficient.

- The tested barrier dissipates the energy of oblique waves more than orthogonal waves.

- At wave period $=1.1 \mathrm{sec}$, as the velocity increases under and behind the breakwater, the wave height decreases behind the breakwater, where the Cartesian coordinates of the horizontal axis ( $\mathrm{x}$ ) are in meters and the vertical axis ( $\mathrm{z}$ ) are in meters.

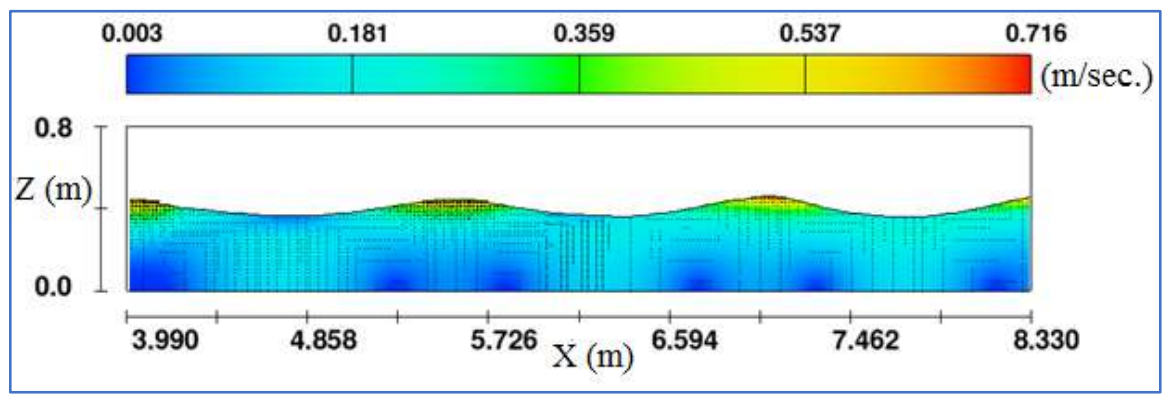

Figure (4) Numerical simulation results

for a barrier-less case (without barriers) 

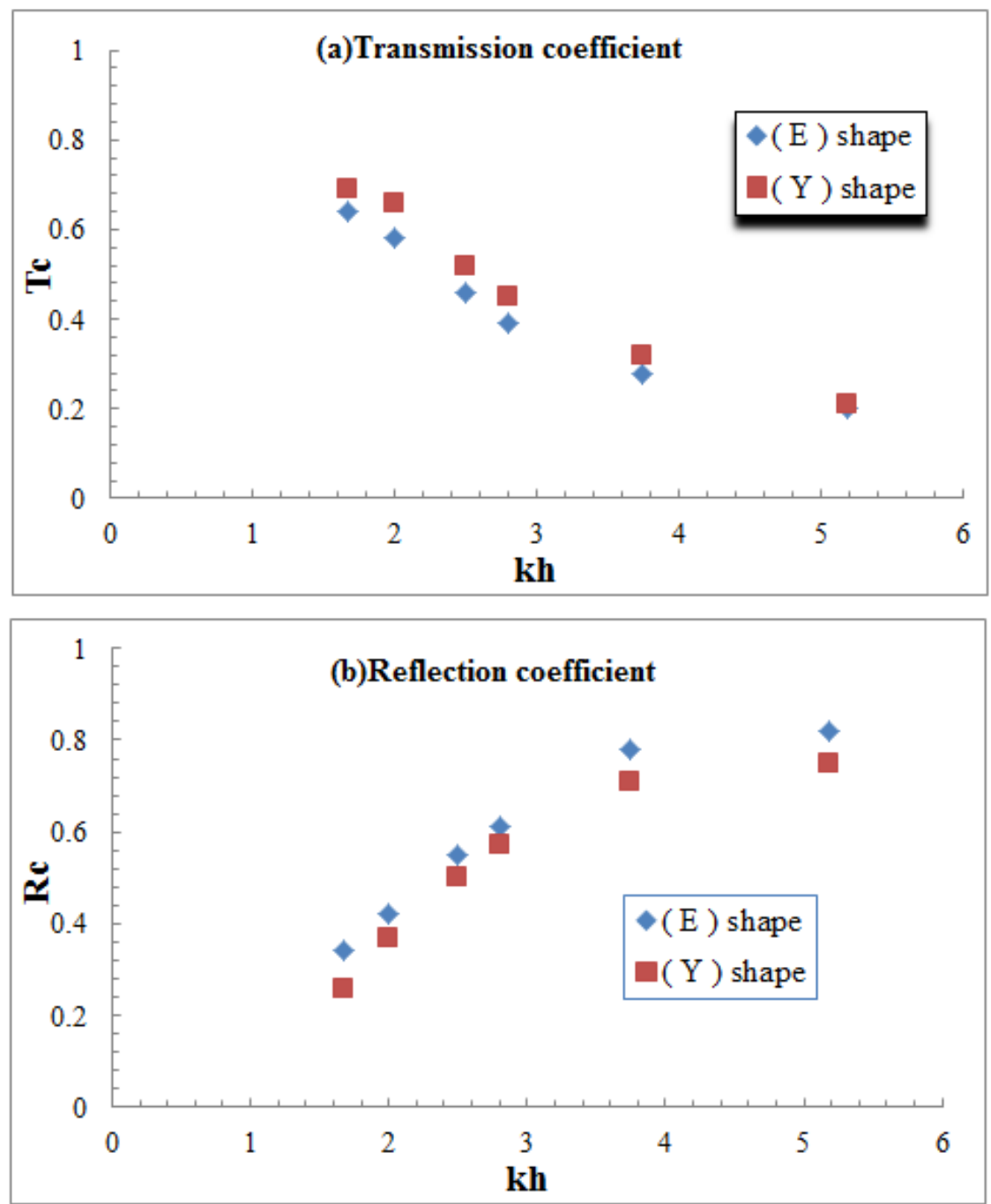

Figure (5) Comparison between E- and Y-shaped in terms of hydrodynamic performance as function (kh) 
INVESTIGATING THE IMPACT OF HALF PIPE BARRIERS ON HYDRODYNAMICS OF WAVES
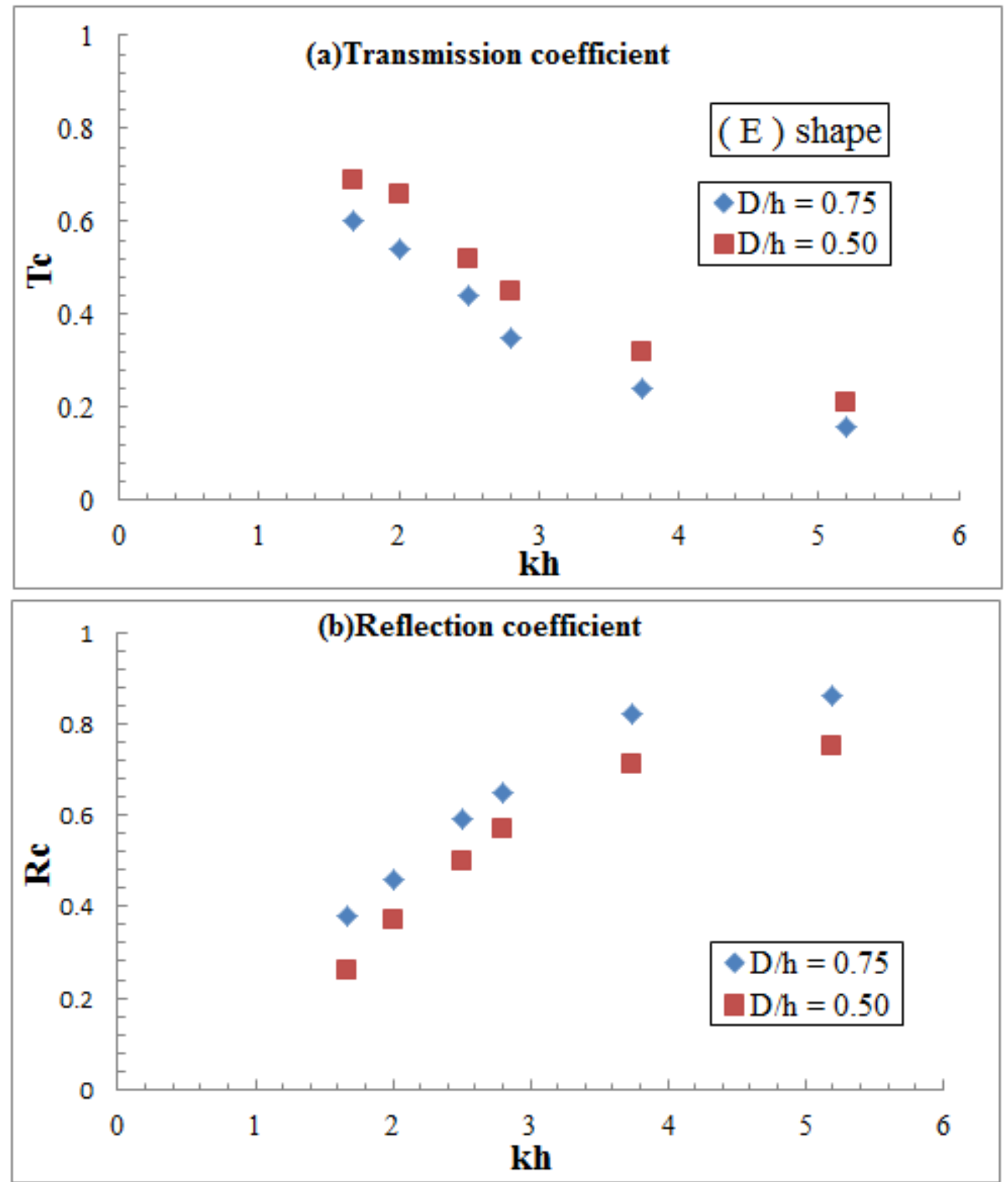

Figure (6) Impact of breakwater draft on hydrodynamic performance efficiency as function $(\mathrm{kh})$ 

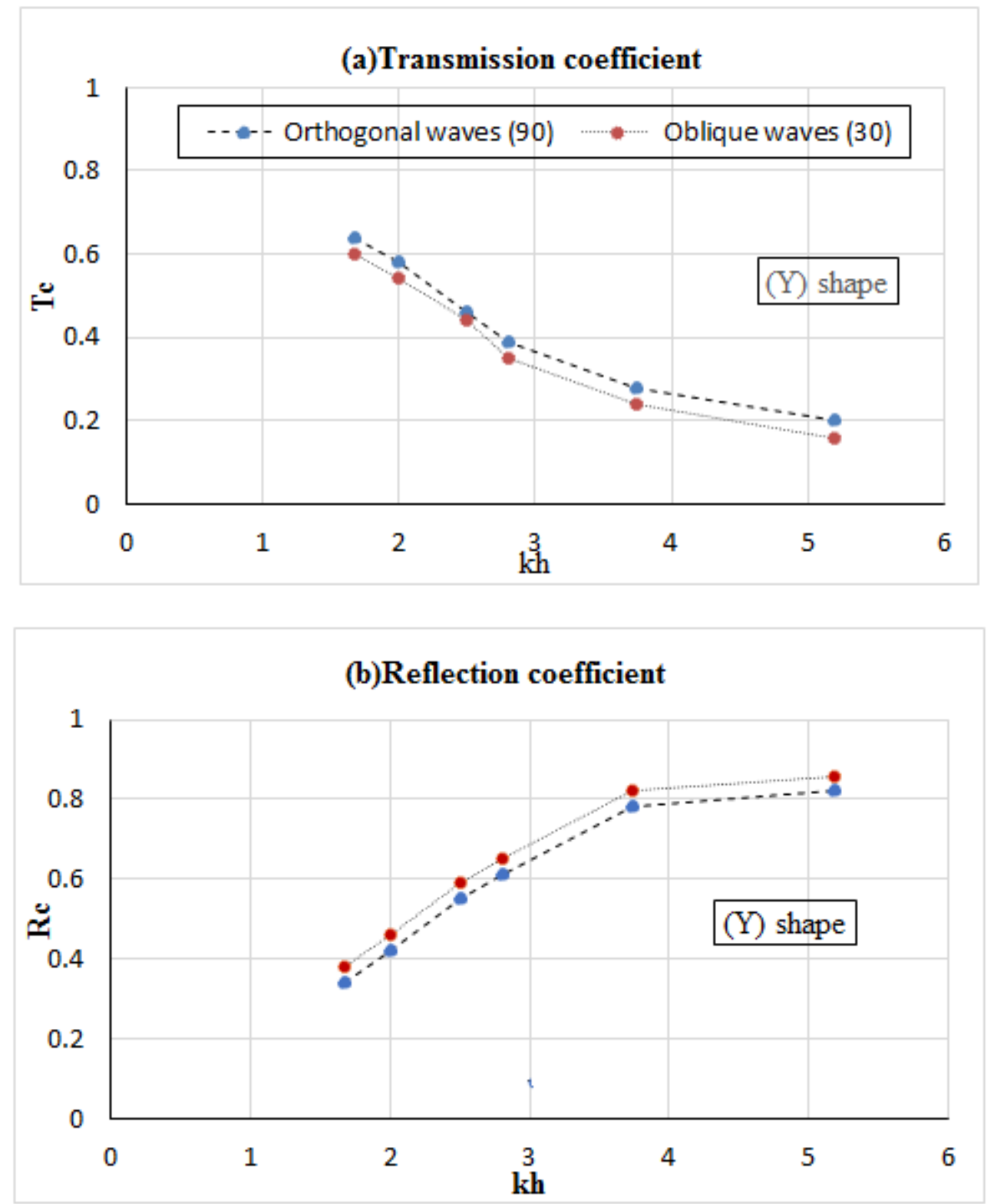

Figure (7) Comparison between orthogonal waves and oblique waves in terms of hydrodynamic performance as function (kh) 


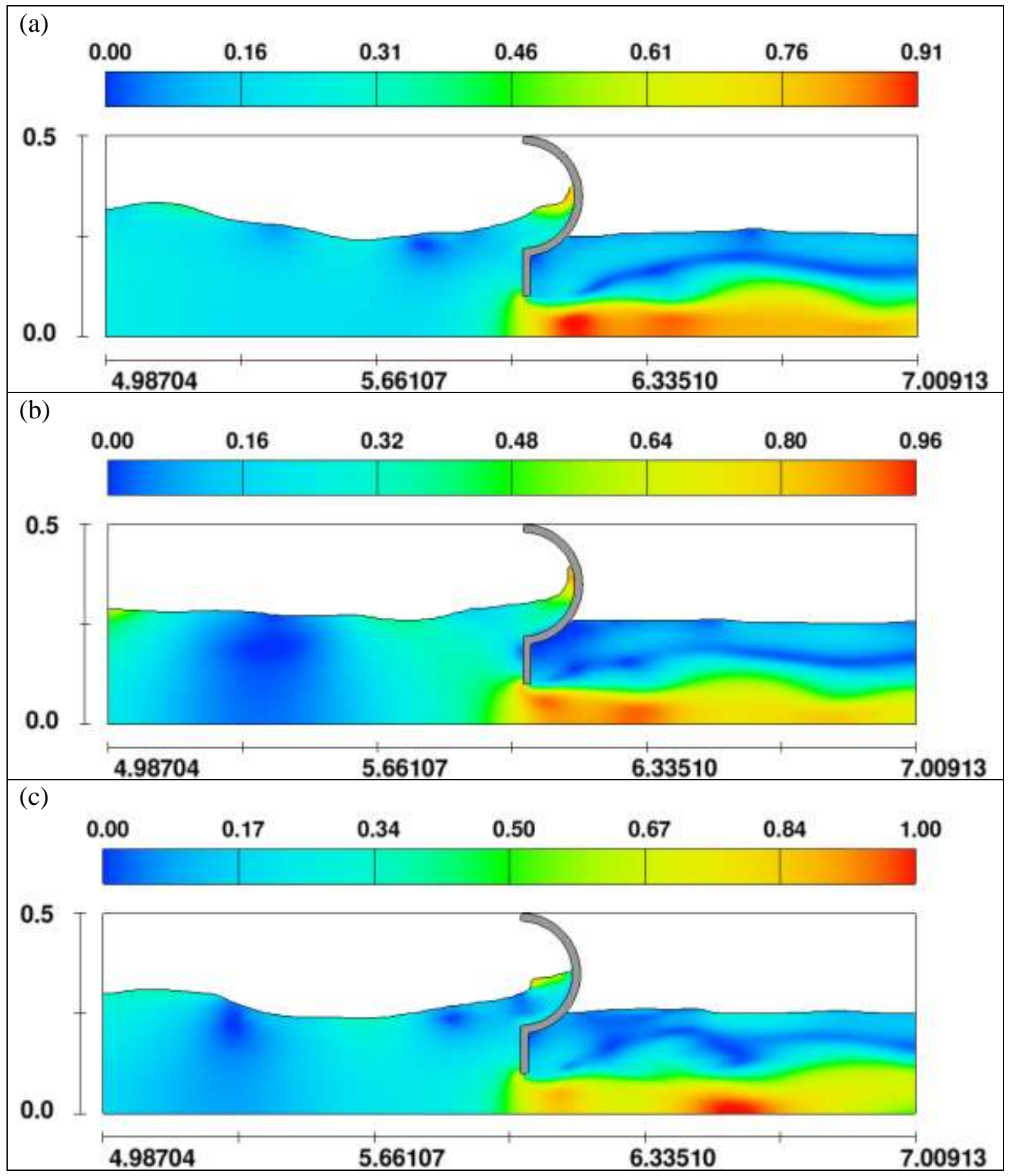

Figure (8) Comparison between velocity and breakwater draft at a wave period of $1.1 \mathrm{sec}$ 


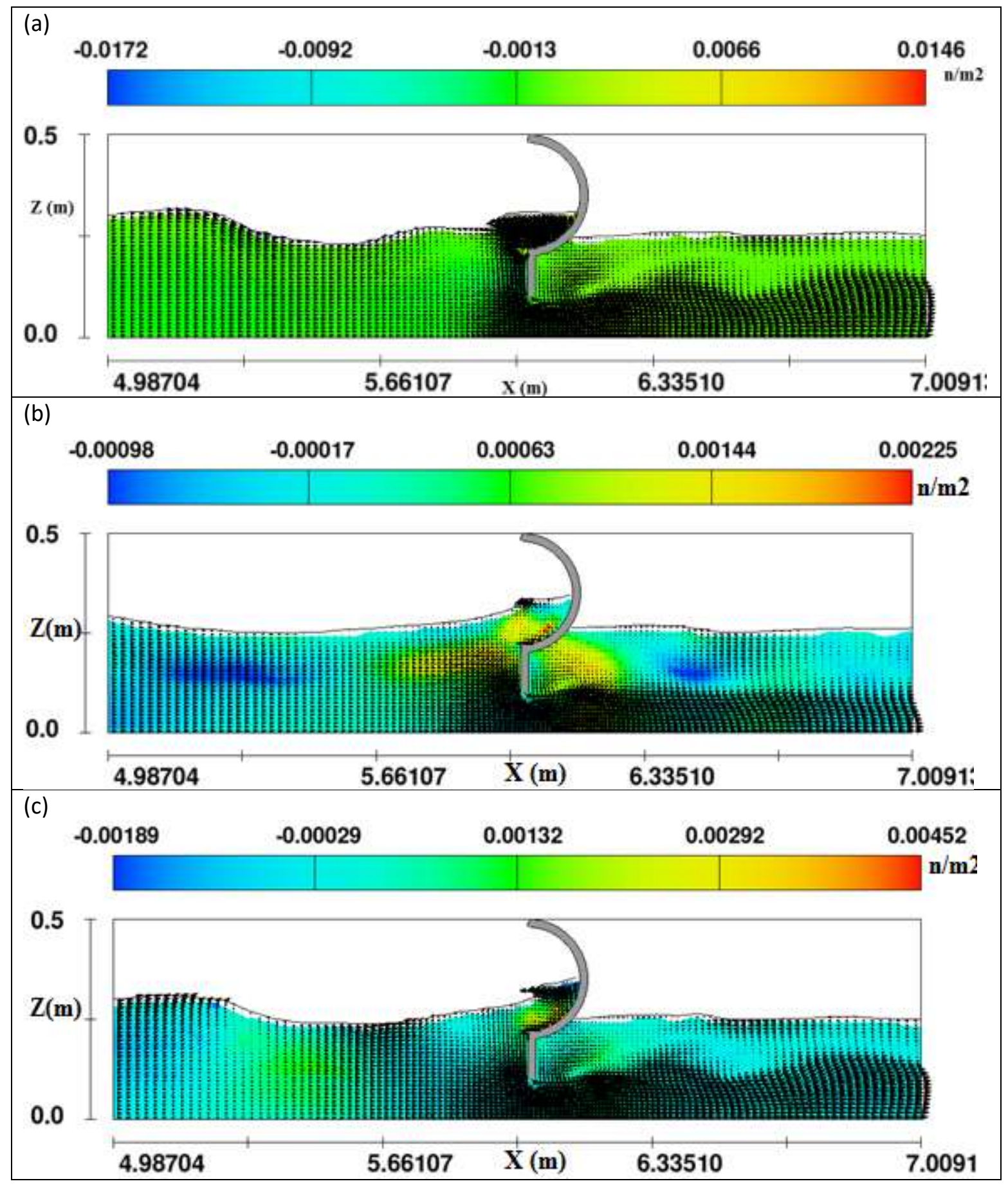

Figure (9) Comparison between pressure and breakwater draft at a wave period of $1.1 \mathrm{sec}$ 


\section{CONCLUSIONS AND RECOMMENDATIONS}

Based on the analyzed results, the following conclusions were deduced:

- The proposed barrier in an E-shaped flume is better than the proposed barrier in a Y-shaped flume, in terms of the hydrodynamic performance.

- The deeper the draft, the lower the transmission coefficient and the higher the reflection coefficient.

- The proposed barrier dissipates the energy of the oblique waves more than the orthogonal waves.

- The deeper the draft, the higher is the velocity, which leads to a reduction in the wave height behind the barrier.

- The higher the reflection of the wave, the greater the hydrodynamic pressure on the barrier.

Based on the deduced conclusions, the following recommendations were suggested:

- Implement the tested barrier within the tested dimensions domain.

- More wave angle values should be investigated.

- Different half pipe breakwater dimensions should be simulated.

\section{REFERENCES}

1. Flow Science Inc. (1997), "Flow-3D Excellent in Flow Modeling Software, Flow$3 \mathrm{D}^{\prime \prime}$

2. Ibrahim, M., and Ahmed, H., (2017), "Using Half Pipes as Permeable Breakwater", J. [IRJET] Vol. 04, No 07. July 2017.

3. Mohamed Ibrahim (2017), "Linear Wave Interaction with Permeable Breakwaters", A Thesis Submitted for Partial Fulfillment of Doctor of Philosophy Degree in Civil Eng., al-Azhar University.

4. Mohamed Ibrahim (2019), "Using a Half Circular Section of the Pipe as a Breakwater for the Ports", Volume 41: Issue No. 3 - July 2019 Civil Engineering Department Al-Azhar University.

5. Nadji Chioukh et al (2017), "Reflection and Transmission of Regular Waves from/Through Single and Double Perforated Thin Walls", China Ocean Eng., 2017, Vol. 31, No. 4, P. 466-475.

6. Version 8.2.User's Manual. los Alamos. NM, 97

7. Wang, J.D., He, G.H., You, R. and Liu, P.F. (2018), "Numerical study on interaction of a solitary wave with the submerged obstacle", Ocean Engineering, $158,1-14$.

8. Xi-zeng Zhao, Du Cheng,(2019) "Experimental and numerical on hydrodynamic characteristic of Solitary waves passing over a submerged breakwater", China Ocean Engineering 33, pages253-267 